\title{
Pubertal induction in adolescents with DMD is associated with high satisfaction, gonadotropin release and increased muscle contractile surface area
}

\author{
Claire L Wood 1,2, Kieren G Hollingsworth², Eric Hughes ${ }^{2}$, Sadhanandham Punniyakodi ${ }^{3}$, Robert Muni-Lofra ${ }^{2,4}$, \\ Anna Mayhew ${ }^{2,4}$, Rod T Mitchell5, Michela Guglieri' ${ }^{2,4}$, Timothy D Cheetham ${ }^{1,2}$ and \\ Volker Straub ${ }^{2,4}$
}

${ }^{1}$ Department of Paediatric Endocrinology, Royal Victoria Infirmary, Newcastle upon Tyne, UK, ${ }^{2}$ Translational and Clinical Research Institute, Faculty of Medical Sciences, Newcastle University, Newcastle Upon Tyne, UK, ${ }^{3}$ Department of Paediatrics, Nobles Hospital, Isle of Man, UK, ${ }^{4}$ John Walton Muscular Dystrophy Research Centre, Newcastle University and Newcastle Hospitals NHS Foundation Trust, Newcastle Upon Tyne, UK, and ${ }^{5}$ MRC Centre for Reproductive Health, Queens Medical Research Institute, Edinburgh, UK

Correspondence should be addressed to C L Wood

Email

claire.wood@ncl.ac.uk

\begin{abstract}
Background: Pharmacological doses of glucocorticoids (GC) reduce inflammation and preserve muscle function in boys with Duchenne muscular dystrophy (DMD). Delayed puberty and bone fragility are consequences of GC treatment. The aim of this study was to determine the acceptability of a 2-year pubertal induction regimen using 4-weekly testosterone injections and examine changes in physique, bone integrity, muscle pathology (assessed by MRI) and muscle function.

Methods: Fifteen prepubertal males with DMD, aged 12-17 years and receiving GC, were treated with an incremental testosterone regimen for 2 years. Participants completed a Treatment Satisfaction Questionnaire (TSQM). Data on BMI, bone density, muscle pathology and function were collected at baseline and 2 years later.

Results: Testosterone injections were well tolerated, with high TSQM scores. Baseline BMI z-score was $2.16(0.90)$ and 1.64 (1.35) 2 years later. Median testosterone levels were $9.7 \mathrm{nmol} / \mathrm{L}$ (IQR: 5.7-11.1) 6-9 months after the last injection with an associated increase in testicular volume. Lumbar spine z-score was 0.22 (s.D. 2.21) at baseline and 0.35 (s.D. 2.21) after 2 years. Upper and lower limb muscle contractile cross-sectional area increased in all participants during the trial ( $P=0.05$ and $P<0.01$, respectively). There was a reduction in $T 2$ relaxation times in most muscle groups with stable upper limb muscle function.

Conclusion: Incremental monthly testosterone injections were well tolerated, promoted endogenous testosterone production and had a positive impact on the skeleton and contractile muscle bulk with evidence suggesting a beneficial impact on the underlying disease process.
\end{abstract}

\section{Introduction}

Duchenne muscular dystrophy (DMD) is a life-limiting genetic disorder that affects 1 in approximately 4000 newborn boys in the UK and occurs due to mutations in the $D M D$ gene (1). Absence of the gene product, dystrophin, leads to increased muscle cell fragility and a cycle of degeneration and repair with inflammatory 
change and replacement of muscle fibres with fibrosis and fat (2). Pharmacological doses of glucocorticoids (GC) - either prednisolone or deflazacort - have had a beneficial impact on longevity and quality of life in DMD (3). Glucocorticoids stabilise muscle strength and have positive effects on cardiovascular and respiratory function (4) and help to reduce scoliosis (5). Unfortunately, longterm high dose GC therapy has side-effects that include slow growth, weight gain, osteopaenia, secondary hypoadrenalism (6) and effects on mood (7). GC also prevent the normal progression into puberty, which can have significant psychological consequences. Exogenous androgen has been used for many years in boys with pubertal delay and is increasingly being used in adolescents with DMD (8). Exogenous androgen can have an anabolic effect on a range of different tissues and could mitigate some of the deleterious effects of GC on muscle, bone and psychological well-being. The increased life expectancy and changing expectations of adolescents with DMD underlines the importance of effective DMD management at this time. As yet, no one has examined the psychological, developmental and skeletal effects of testosterone in a prospective manner with a detailed examination of bone and muscle phenotype. A retrospective audit identified 14 boys who had been treated with testosterone for induction of puberty and highlighted the lack of consensus in terms of regimen, length of treatment or age at initiation (8). This study investigated the efficacy and tolerability of a 2-year regimen of incremental, intramuscular testosterone to induce puberty in a cohort of GC-treated adolescents with DMD.

\section{Methods}

\section{Participants}

Participants were from a single centre study that followed 15 adolescents with DMD and delayed puberty as they were treated with testosterone. Full details of the clinical trial and protocol have been published (9). Briefly, 15 prepubertal males between 12 and 17 years old were treated with a stepwise regimen of testosterone injections every 4 weeks. Data were collected to determine the effectiveness and tolerability of the treatment regimen. Inclusion and exclusion criteria are in the Supplementary Methods section (see section on supplementary material given at the end of the article).

\section{Outcomes}

Primary outcome

The primary outcome measure was Treatment Satisfaction Questionnaire for Medication (TSQM) (10).

\section{Secondary outcomes}

The secondary outcome measures were:

- Auxological assessment including height, weight and pubertal status (11)

- Biochemical assessment of pubertal stage

- Bone age

- Muscle cross-sectional area (CSA), contractile crosssectional area (CCSA) and fat fraction (FF) determined by muscle MRI of upper and lower limbs, and T2 relaxation time of the upper limb.

- Motor performance evaluated using North Star Ambulatory Assessment (NSAA) and Performance of Upper Limb (PUL)

- Bone mineral adjusted density of the lumbar spine and total body (minus head) using Dual-energy x-ray absorptiometry (DXA)

\section{Testosterone regimen}

The incremental testosterone regimen involved the administration of testosterone (Sustanon 250) by deep intramuscular injection over a 2-year period:

- Sustanon $50 \mathrm{mg}(0.2 \mathrm{~mL})$ every 4 weeks for 12 weeks

- Sustanon $100 \mathrm{mg}(0.4 \mathrm{~mL})$ every 4 weeks for 40 weeks

- Sustanon $150 \mathrm{mg}(0.6 \mathrm{~mL})$ every 4 weeks for 24 weeks

- Sustanon $250 \mathrm{mg}(1 \mathrm{~mL})$ every 4 weeks for 28 weeks

A 4 weekly injection regimen is commonly used in the UK and had the additional advantage of reducing the need for visits to hospital or the local surgery when compared to a more intensive regimen with a shorter interval between injections.

\section{Assessment}

Patient satisfaction

The TSQM is self-administered and used at baseline and 6 monthly thereafter. It is a 14-item instrument, yielding four subscale scores: global satisfaction, effectiveness, adverse events and convenience and has been validated 
for adults with chronic disease (10). The total score (excluding side-effects domain as these are only answered if the participant felt there were associated side-effects) was the primary outcome measure.

\section{Clinical assessment}

Height/arm span and weight were measured. Target height was calculated using: (mother + father's height) $/ 2+13 \mathrm{~cm}$. Testicular size was assessed using a Prader orchidometer and pubertal staging determined using Tanner Staging criteria (11). Assessments were conducted by CW or TC and cross-checked in over $75 \%$ of the patients.

\section{Biochemical gonadal/androgen status}

Biochemical pubertal status was determined by measuring morning (pre-10.00) serum testosterone, luteinising hormone (LH) and follicle-stimulating hormone (FSH) concentrations at $0,6,12,18,24,27$ and 30-33 months. Levels were also measured between 6 and 9 months after their last testosterone injection, as part of routine clinical follow-up.

\section{Bone age}

Bone age was assessed at baseline and 2 years using a radiograph of the left wrist and reported by a consultant radiologist (12).

\section{Motor function and muscle strength}

All participants performed PUL (Version 2.0) for assessing upper limb performance (13) and ambulatory patients also undertook the NSAA (14).

\section{Bone mineral density}

DXA scans were conducted annually using a Lunar iDXA (GE Lunar Corp, Madison, WI USA) to assess lean vs total body mass and enable calculation of bone mineral content (BMC), adjusted for age, size and gender. Adjusted z-scores of lumbar spine (L1-4) and total body (minus head) were recorded.

\section{MRI data acquisition and image processing}

Imaging was performed on a 3.0T scanner (detailed protocols in Supplementary Methods). Briefly, quantitative Dixon FF imaging was collected using five-fold compressed sensing acceleration $(15,16)$. For the upper limb, quantitative Dixon FF imaging and T2 relaxation time imaging (a surrogate of muscle inflammation (17)) was performed and maps processed. Regions of interest (ROIs) were defined for the upper and lower limb for multiple image slices and FF and T2 relaxation times were calculated together as area-weighted averages. CSA and cCSA were also calculated to quantify the area of viable muscle tissue remaining (18). Results are presented for muscle groups across all participants, and for individual participants across all their muscle groups.

All participants consented to an MRI scan at baseline, 1 and 2 years. Six healthy male controls, matched by bone age (as all participants in the trial had delayed puberty and bone age), underwent the same MRI protocol.

\section{Statistical analysis}

This was an observational study and the primary outcome (treatment satisfaction) was not subject to a power calculation. The recruitment target was pragmatic and reflected the local population of boys with DMD and pubertal delay who were not already enrolled in a clinical trial. All data are presented as mean \pm S.D. unless stated otherwise. Independent t-tests were used to compare baseline measurements of DMD boys to healthy control participants. Paired $t$-tests (or Wilcoxon rank-sum techniques if variables not normally distributed) were used to compare outcome measures before and after testosterone administration. Statistical significance was taken to be $P<0.05$. Stata v15 was used for statistical analysis.

\section{Ethical approval}

The study was approved by York Research Ethics Committee. Informed consent was obtained from the patient if $>16$ years and from the parent/guardian with patient assent if $<16$ years.

\section{Results}

\section{Baseline characteristics}

Recruitment commenced in December 2015 until November 2016. 17 patients were approached, 16 agreed to take part and were screened and 15 were eligible (see Fig. 1 and protocol (9)). The last participant's final visit was February 2019. Participants were aged 12.0-16.9 
16 patients invited for screening

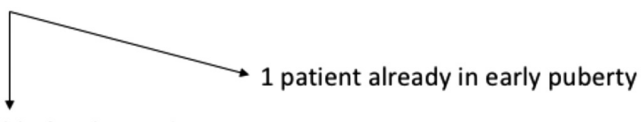

15 patients eligible for the study

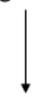

15 patients recruited to the study

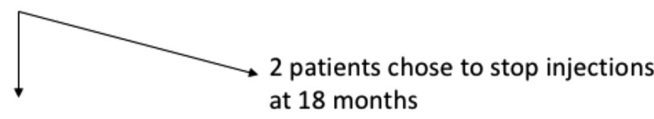

13 patients received 2 years of Sustanon

injections

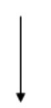

15 patients completed all study visits

\section{Figure 1}

Flowchart of study participants.

years (mean: 13.8 years, mean bone age: 9.4 years) at baseline (Table 1). Controls were matched to bone age; their chronological age ranged from 7.9 to 12.9 years (mean: 10.0 years), all controls were prepubertal. In total, 3/15 participants were non-ambulant at baseline. All participants had been on GC therapy for a mean of 8.1 years at recruitment (Table 2); regimens were unchanged during the study.

Two participants (15 and 16) in the study were happy with their pubertal development after 18 months of intramuscular testosterone and stopped injections but completed all scheduled visits. These are highlighted with asterisks in figures and tables.

Table 1 Baseline characteristics of participants. Data are presented as mean (S.D.).

\begin{tabular}{|c|c|c|c|}
\hline & Overall & $\begin{array}{c}\text { Ambulant } \\
(n=12)\end{array}$ & $\begin{array}{c}\text { Non-ambulant } \\
\qquad(n=3)\end{array}$ \\
\hline $\begin{array}{l}\text { Age at baseline } \\
\text { (years) }\end{array}$ & $13.8(1.50)$ & $13.7(1.42)$ & 14.4 (1.99) \\
\hline $\begin{array}{l}\text { Bone age at } \\
\text { baseline (years) }\end{array}$ & $9.4(2.2)$ & $9.1(2.2)$ & $10.5(2.3)$ \\
\hline $\begin{array}{l}\text { Time on steroids } \\
\text { (years) }\end{array}$ & $8.4(2.2)$ & $8.4(1.2)$ & $8.7(4.9)$ \\
\hline $\begin{array}{l}\text { Deflazacort dose } \\
\quad(\mathrm{mg} / \mathrm{kg}), n=9\end{array}$ & $0.55(0.13)$ & $0.56(0.14)$ & $0.44(-)$ \\
\hline $\begin{array}{l}\text { Prednisolone dose } \\
\quad(\mathrm{mg} / \mathrm{kg}), n=6\end{array}$ & $0.47(0.13)$ & $0.51(0.15)$ & $0.41(0.11)$ \\
\hline NSAA score & $13.7(9.8)$ & $13.7(9.8)$ & - \\
\hline PUL score & $33.9(6.7)$ & $34.3(7.1)$ & $32.7(6.1)$ \\
\hline
\end{tabular}

NSAA, North Star Ambulatory Assessment; PUL, performance of the upper limb.

\section{Treatment satisfaction for medication questionnaire}

The mean total TSQM was 48.5 (s.D. 6.2, range: 37-59) out of a possible 59 points, with similar scores in each domain (Fig. 2 and Table 3). To the nearest integer, the mean score for all but one treatment domain was 6 ('very satisfied'). When considering time to effect, the mean score was 5 ('satisfied'). Two patients felt that they had experienced side-effects from the IM testosterone regimen. Their responses corresponded with the adverse events profile recorded by the study team (Supplementary Results).

\section{Pubertal status}

All patients were either Tanner stage G1P1, G2P1 or G1P2 and had a testicular volume of $<4 \mathrm{~mL}$ at baseline. Initial testosterone levels were $<2.0 \mathrm{nmol} / \mathrm{L}$ with suppressed $\mathrm{LH}$ and FSH levels (median LH: < 0.1IU/L (IQR: < 0.1, 0.1), median FSH: 1.2 IU/L (IQR: 1.1, 1.8)). By the 2-year visit, patients were Tanner stage G4P4 to G5P5 and median testosterone level was 8.3nmol/l (IQR: 5.7-17.9) 3-5 weeks after their last injection. Testicular volume was $\leq 5 \mathrm{~mL}$ in all (mean: 2.8, s.D. 2.9, range: $1.5-5 \mathrm{~mL}$ ) after 2 years and LH/FSH levels remained suppressed (median LH: $<0.1$ IU/L (IQR: 0.1, 0.1), median FSH: <0.1IU/L (IQR: 0.1, 1.2)). By 3 months after the last Sustanon injection, activation of the hypothalamo-pituitary axis (HPA) was evident with a significant increase in both $\mathrm{LH}$ and FSH (median LH: 6.7 IU/L (IQR: 5.9, 8.8), $P<0.01$, median FSH: 6.0 IU/L (IQR: 4.4, 8.0), $P<0.01$ ) compared to baseline. In keeping with this, the median testosterone level 3 months after the last injection was $7.5 \mathrm{nmol} / \mathrm{L}$ (IQR: 5.5-12.8- available in 13/15 patients - two stopping treatment early). By 6-9 months after the last injection, the testosterone level was $9.7 \mathrm{nmol} / \mathrm{L}$ (IQR: 5.7-11.1). Mean testicular volume 6-9 months after last injection was $6.9 \mathrm{~mL}$ (1.9), significantly greater than the baseline $2.2 \mathrm{~mL}$ (s.D. $0.2 ; P<0.001$ ). In keeping with this, $\mathrm{LH}$ and FSH levels also remained significantly raised compared to baseline at $5.3 \mathrm{IU} / \mathrm{L}$ (IQR: 3.2-5.9, $P<0.001$ ) and 7.9 IU/L (IQR: 5.1-10.4, $P<0.001$ ), respectively. (Fig. 3)

\section{Muscle function}

The mean NSAA score at baseline for ambulant participants was 13.7 (s.D. 9.8) (Table 4). The mean PUL score at baseline was 33.9 (s.D. 6.7) and was not directly correlated with ambulatory status (Table 1). PUL score was 
Table 2 Individual patient characteristics.

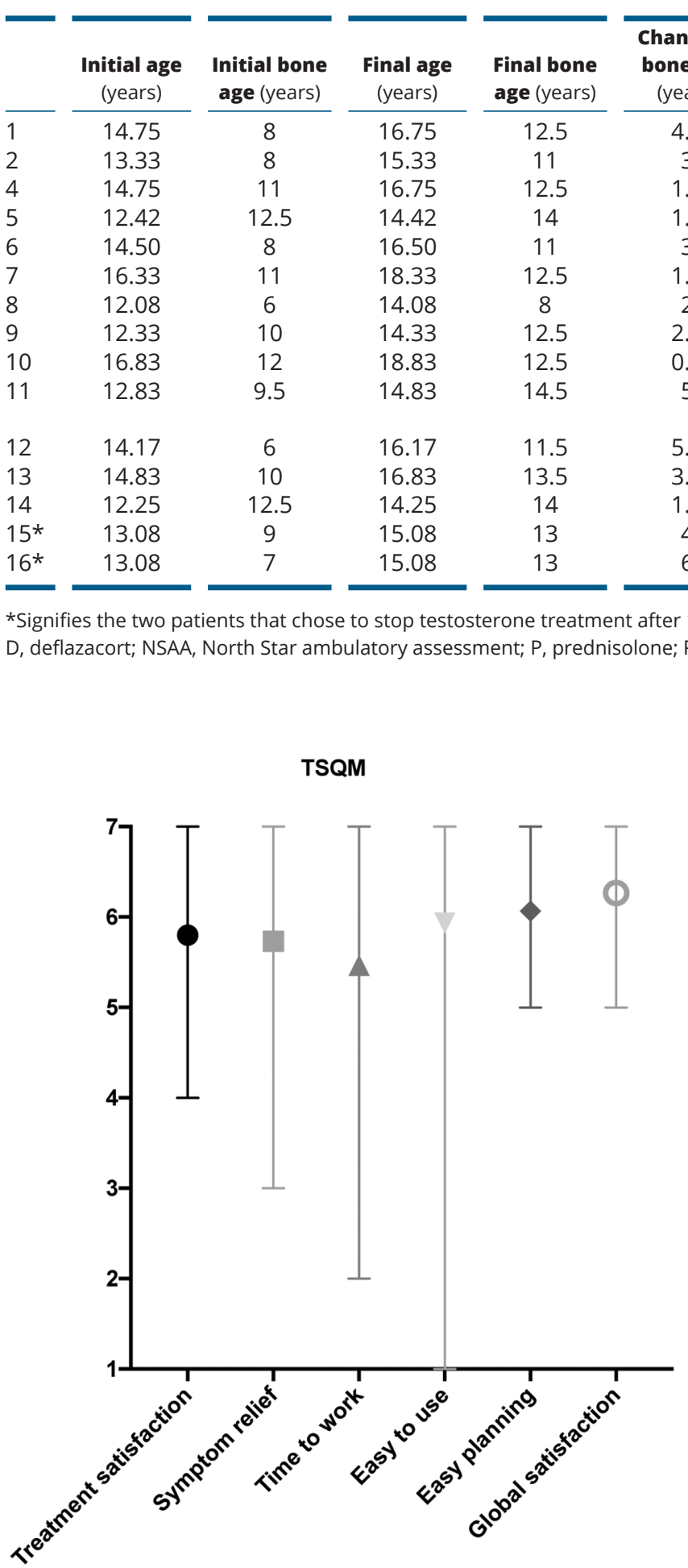

Figure 2

A summary of the scores from some of the key domains from the TSQM at the end of the 2-year period. The symbol denotes the mean value for each domain, the whisker represents the range.
30.9 (s.D. 8.7) at final assessment which was no different to baseline. Five participants lost ambulation during the 2-year study period, so that only eight completed the NSAA at the final visit. For those with initial and final NSAA scores, mean initial NSAA score was 18.0 (s.D. 8.9, range: 6-30) and final NSAA score 13.0 (s.D. 7.2, range: 4-24) (Table 5).

\section{Anthropometric variables}

Baseline height z-score was -3.17 (s.D. 1.34) and -3.44 (s.D. 1.06) after 2 years. The mean 2 -year height gain was $8.8 \mathrm{~cm}$ (s.D. 5.2). The baseline BMI z-score was 2.16 (s.D. 0.90 ) with a mean change of -0.45 (s.D. -3.2 ) over 2 years, giving a final BMI z-score of 1.64 (s.D. 1.35). There was no change in fat mass or lean mass index during the study (Fig. 4 and Tables 4 and 5).

\section{Bone mineral density}

Initial lumbar spine size-adjusted z-score was 0.22 (s.D. 2.21, range: -3.95 to +5.22 ) After 2 years of testosterone treatment, the lumbar spine size-adjusted $\mathrm{z}$-score was 0.35 (s.D. 2.21 , range: -2.75 to +3.98 ).

\section{Bone age}

Bone age advanced in all patients during the study period (Tables 1 and 2); mean change was 3.0 years (s.D. 1.7). 
Table 3 TSQM questionnaire data.

\begin{tabular}{|c|c|c|c|c|c|c|c|c|c|c|c|}
\hline & \multicolumn{3}{|c|}{ Effectiveness scale: 1-7 } & \multicolumn{5}{|c|}{ Side-effects scale: 1-5 } & \multicolumn{3}{|c|}{ Convenience scale: 1-7 } \\
\hline & Q1 & Q2 & Q3 & Q4 & Q5 & Q6 & Q7 & Q8 & Q9 & Q10 & Q11 \\
\hline 1 & 7 & 7 & 6 & No & & & & & 6 & 6 & 5 \\
\hline 2 & 7 & 7 & 5 & No & & & & & 6 & 6 & 6 \\
\hline 4 & 7 & 7 & 7 & No & & & & & 7 & 5 & 5 \\
\hline 5 & 6 & 6 & 6 & Yes & 2 & 1 & 1 & 1 & 6 & 6 & 2 \\
\hline 6 & 7 & 7 & 7 & No & & & & & 7 & 7 & 7 \\
\hline 7 & 5 & 4 & 5 & No & & & & & 6 & 5 & 5 \\
\hline 8 & 4 & 3 & 5 & No & & & & & 6 & 6 & 7 \\
\hline 9 & 7 & 7 & 7 & No & & & & & 7 & 7 & 6 \\
\hline 10 & 6 & 4 & 5 & No & & & & & 7 & 7 & 7 \\
\hline 11 & 6 & 6 & 6 & No & & & & & 6 & 6 & 6 \\
\hline 12 & 6 & 6 & 6 & Yes & 1 & 1 & 1 & 1 & 6 & 6 & 5 \\
\hline 13 & 6 & 6 & 5 & No & & & & & 6 & 5 & 5 \\
\hline 14 & 5 & 5 & 5 & No & & & & & 7 & 7 & 6 \\
\hline $15^{*}$ & 4 & 7 & 5 & No & & & & & 5 & 5 & 5 \\
\hline $16 *$ & 4 & 4 & 2 & No & & & & & 1 & 7 & 7 \\
\hline
\end{tabular}

\begin{tabular}{|c|c|c|}
\hline Q12 & Q13 & $\mathrm{Q}^{14}{ }^{\dagger}$ \\
\hline 5 & 5 & 7 \\
\hline 4 & N/A & 7 \\
\hline 4 & 3 & 6 \\
\hline 4 & 5 & 7 \\
\hline 5 & 5 & 7 \\
\hline 3 & 3 & 5 \\
\hline 4 & 3 & 5 \\
\hline 5 & 5 & 7 \\
\hline 3 & 3 & 5 \\
\hline 4 & 3 & 6 \\
\hline 5 & 5 & 6 \\
\hline 4 & 4 & 7 \\
\hline 5 & 5 & 7 \\
\hline 3 & 2 & 5 \\
\hline 3 & 3 & 7 \\
\hline
\end{tabular}

Q4 is a dichotomous response option with a conditional skip to Q9. Where a scale of 1-7 was used, 1 indicates 'extremely dissatisfied', 7 indicates 'extremely satisfied'. Within the scale of 1-5, 1 indicates 'not at all' while 5 indicates 'extremely'.

'Scale of 1-7 was used; *participants happy with pubertal development after 18 months of intramuscular testosterone and stopped injections but completed all scheduled visits.

N/A, no data available.

\section{Muscle MRI}

\section{Cross-sectional comparison of DMD participants vs controls}

Data were obtained from the legs of 5 healthy controls and the arms of 6 healthy controls. Arm and leg muscle MRI data were obtained for 14 DMD participants who attended at baseline, 1 and 2 years.

For leg muscle groups, the muscle FF was higher in DMD participants than controls ( $P \leq 0.001$, Table 6$)$, with a wide variation in leg muscle pathology of individuals (Fig. 5A). The tibial bone marrow FF of DMD boys was also higher than controls at baseline $(99.3 \%$ vs $88.9 \%, P=0.02$, Table 6).

All arm muscles had higher FF for DMD participants than controls $(P<0.01$, Table 7$)$. The extent of arm muscle involvement varied considerably between individuals (Fig. 5B). T2 relaxation times were higher in DMD patients at baseline $(P$ values $<0.01)$ than controls (Table 7$)$. The difference between $\mathrm{T} 2$ times of participants and controls at baseline was least marked for the UFG (1.3 ms vs 2.6$3.0 \mathrm{~ms}$, Table 7).

\section{Longitudinal changes in MRI data}

The bone marrow FF was constant over time (Table 6). There were no significant longitudinal changes in mean FF of any individual leg muscle (Table 6), and when leg muscle groups were combined, there were no significant changes in FF during the 2-year period. When all muscle groups were combined, there were significant increases in both CSA and cCSA between baseline and 2 years $(P<0.001$ and $P<0.01$, respectively). When CSA of combined muscle groups for individuals was analysed, eight participants had a significant change in CSA over 2 years. By individual muscle group, cCSA only increased in the tibialis anterior.

\section{Longitudinal changes in MRI arm data}

There was a significant increase in FF of the upper arm flexor group (UFG) (Table 7) over the 2-year period. Arm FF remained unchanged in most participants/muscle groups over the 2-year period (Fig. 5B and Table 7). When all arm muscle groups were combined, both CSA and cCSA increased $(P=0.004$ and $P=0.05)$. The CSA was greater in all four muscle groups at 2 years (Table 7$)$. The only significant change in arm cCSA overtime was in the forearm extensor group (FEG), with increases at 1 and 2 years compared to baseline (Table 7).

The T2 relaxation times for all groups except UFG decreased significantly at 2 years post-baseline but remained higher than controls (Table 7).

\section{Discussion}

The newly revised standards of care highlight the importance of the timely recognition and management 

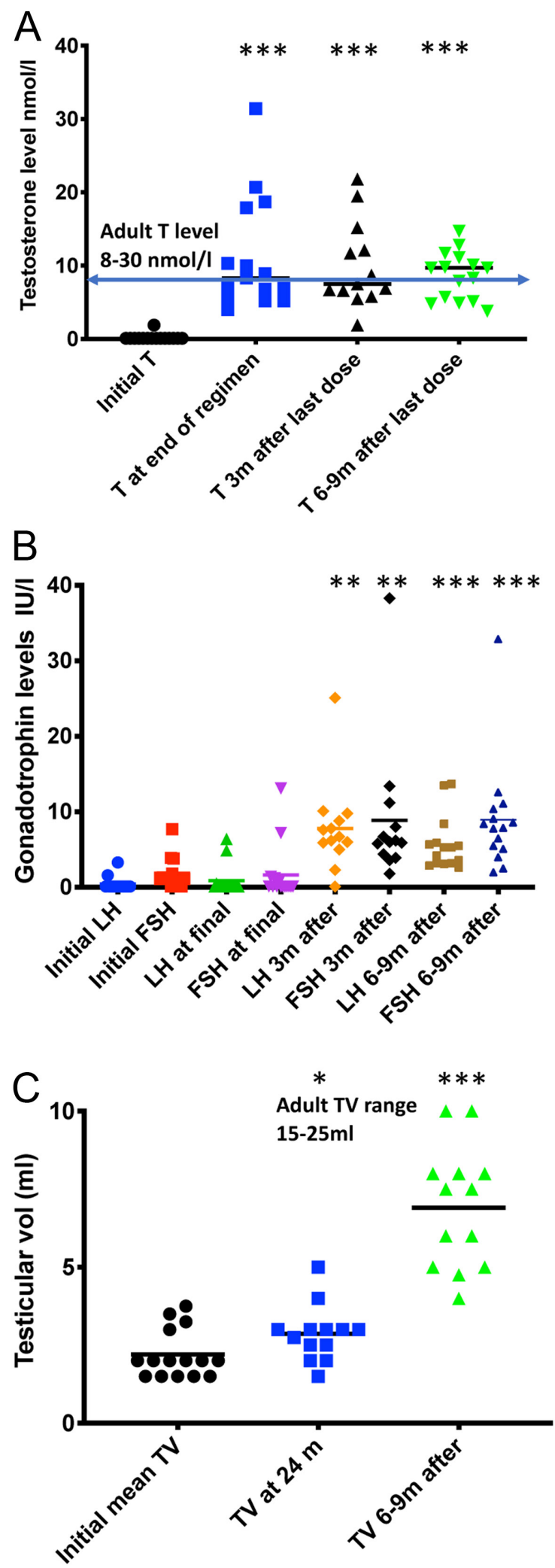

Figure 3

(A) Testosterone levels at the beginning and end of the 2-year regimen and at 3 and 6-9 months after the last Sustanon of pubertal delay in DMD (19) and this is the first study that has prospectively evaluated pubertal induction in adolescents with DMD. Our data support the use of androgen in DMD boys on GC with evidence of benefit in many of the parameters studied. Monthly incremental injections of Sustanon were well tolerated with adolescents being mainly 'very satisfied'. The participant who awarded a value of 1 to the question, 'Is the treatment easy to use?' probably did so in error, as they awarded the maximum score of 7 to the other questions. The only domain in which the score was lower was 'time to work' where participants were 'satisfied'.

All patients were in late puberty after 2 years. The increase in gonadotropin levels and testicular volume, which occurred by 3 months and persisted at 6-9 months after the last Sustanon injection, suggested activation of the hypothalamo-pituitary gonadal (HPG) axis and endogenous testosterone production after the cessation of exogenous testosterone. It is unclear whether a degree of HPG axis suppression will persist as a result of the chronic GC use. There was variability in terms of testicular volume, androgen and gonadotrophin levels, suggesting that there may be additional factors affecting the HPG axis including relative sensitivity to $\mathrm{GC}(20,21)$. It will be important to determine their ongoing gonadal and androgen status.

There was a mean height increase of $8 \mathrm{~cm}$ over 2 years, substantially more than the median height velocity of only $0.45 \mathrm{~cm} /$ year in the year preceding pubertal induction described previously in DMD (8). Short stature is a key concern in this population (6), and many adolescents would like to be taller and look more like their peers. Whilst a large height gain may not be advantageous (22), a small height gain during puberty is likely to be welcomed by the patients.

Delayed bone age in adolescents with DMD is multifactorial, but largely related to delayed puberty and growth retardation $(23,24)$. Bone age increased at a greater rate than chronological age suggesting that epiphyseal

injection. Horizontal line shows mean value. Blue horizontal arrow shows normal adult testosterone range. $* \star * P<0.001$ for value compared to baseline. (B) Gonadotrophin ( $\mathrm{LH}$ and $\mathrm{FSH}$ ) levels at the beginning and end of the 2-year regimen and at 3 and 6-9 months after the last Sustanon injection. Horizontal line shows mean value. ${ }^{* *} P<0.01, * * * P<0.001$ for value compared to baseline. (C) Testicular volumes at the beginning and end of the 2-year regimen and at 6-9 months after the last Sustanon injection. Horizontal line shows mean value. $* P<0.05, * \star \star P<0.001$ for value compared to baseline. 
Table 4 Pubertal characteristics.

\begin{tabular}{|c|c|c|c|c|c|c|c|c|c|}
\hline \multicolumn{5}{|c|}{ Initial } & \multicolumn{5}{|c|}{ At the end of regimen } \\
\hline TS & LH & $\mathrm{FSH}$ & TV & $\begin{array}{l}\text { Tanner } \\
\text { stage } \\
\end{array}$ & TS & LH & FSH & TV & $\begin{array}{l}\text { Tanner } \\
\text { stage } \\
\end{array}$ \\
\hline 0.1 & $<0.1$ & 1.1 & 1.5 & G1P1 & 10 & 0.1 & 1.4 & 1.5 & G5P4 \\
\hline 0.1 & $<0.1$ & 1.3 & 2 & G1P2 & 18.7 & 0.1 & 0.1 & 2.5 & G4P4 \\
\hline 1.9 & 3.3 & 3.8 & 3.5 & G2P1 & 10.3 & 4.9 & 13.1 & 3 & G4P4 \\
\hline 0.1 & $<0.1$ & 0.5 & 1.5 & G1P1 & 8.3 & 0.1 & 0.1 & 3 & G4P4 \\
\hline 0.1 & 1.6 & 7.7 & 3 & G1P2 & 17.9 & 0.1 & 0.1 & 4 & G4P4 \\
\hline 0.1 & $<0.1$ & 1.8 & 3.75 & G1P1 & 5.2 & 0.5 & 0.1 & 3 & G4P5 \\
\hline 0.1 & $<0.1$ & 1.2 & 1.5 & G1P2 & 20.7 & 0.1 & 0.1 & 3 & G5P5 \\
\hline 0.1 & $<0.1$ & $<0.1$ & 2 & G1P1 & 5.7 & 0.1 & 1.2 & 2 & G5P4 \\
\hline 0.1 & $<0.1$ & $<0.1$ & 1.5 & G1P2 & 6.9 & 0.1 & 0.1 & 2.5 & G5P4 \\
\hline 0.1 & $<0.1$ & $<0.1$ & 2 & G1P1 & 6.8 & 0.1 & 0.1 & 3 & G5P5 \\
\hline 0.1 & $<0.1$ & 1.1 & 2 & G1P1 & 8.9 & 0.1 & 0.1 & 5 & G5P5 \\
\hline 0.1 & $<0.1$ & 1.1 & 2 & G2P2 & 7.4 & 0.1 & 0.7 & 2 & G4P4 \\
\hline 0.1 & $<0.1$ & 1.3 & 1.5 & G1P1 & 31.4 & 0.1 & 0.1 & 2.75 & G5P5 \\
\hline 0.1 & $<0.1$ & 3.9 & 3.25 & G2P1 & 4 & 0.1 & 0.1 & 2 & G4P4 \\
\hline 0.1 & $<0.1$ & 1.1 & 2 & G1P2 & 5.2 & 6.4 & 7.2 & 3 & G5P5 \\
\hline
\end{tabular}

\begin{tabular}{|c|c|c|c|c|c|c|}
\hline \multicolumn{3}{|c|}{ After 3 months } & \multicolumn{4}{|c|}{ After 6-9 months } \\
\hline TS & $\mathrm{LH}$ & FSH & TS & LH & $\mathrm{FSH}$ & TV \\
\hline 15.2 & 8.8 & 3.6 & 14.7 & 3.2 & 5.5 & 4.75 \\
\hline 21.8 & 5 & 1.8 & 11.1 & 3.6 & 2.5 & 10 \\
\hline 19.5 & 6.2 & 11.2 & 9.7 & 3.2 & 11.1 & 8 \\
\hline 7.5 & 9.8 & 4.4 & 5.7 & 2.6 & 4 & 8 \\
\hline 12.1 & 25.1 & 38.3 & 11.7 & 13.7 & 32.9 & 5 \\
\hline 6.6 & 5.9 & 13.4 & 5.1 & 8.4 & 12.6 & 8 \\
\hline 8.7 & 6.7 & 6.7 & 9.7 & 5.9 & 6.5 & 4 \\
\hline 5.5 & 7.6 & 8 & 7.9 & 5.3 & 8.6 & 10 \\
\hline 1.9 & 0.1 & 3.9 & 3.8 & 13.5 & 9.1 & 4 \\
\hline 6.7 & 6 & 6 & 10.1 & 5.5 & 8.4 & - \\
\hline 11.7 & 7.8 & 5.9 & 9.8 & 4.2 & 5.1 & 5 \\
\hline 6.9 & 10.1 & 3.6 & 8.3 & 3.1 & 2.0 & - \\
\hline 1.3 & 2.3 & 1.8 & 4.9 & 5.7 & 10.4 & - \\
\hline- & - & - & 4.8 & 2.9 & 7.8 & 7.5 \\
\hline- & - & - & 12.8 & 5.3 & 7.9 & 6 \\
\hline
\end{tabular}

Testosterone (TS) was measured in nmol/l, FSH and LH in IU/L, testicular volume (TV) in $\mathrm{mL}$ (mean of left and right volumes).

*Signifies the two patients that chose to stop testosterone treatment after 18 months.

maturation was taking place despite the presence of pharmacological doses of GC.

Low BMD and fracture are well-recognised complications in DMD, both as a consequence of the disease process itself and chronic GC use. Although this study was not powered to look in detail at bone health or body composition, it appears that the testosterone regimen stabilised BMD. However, as shown in Fig. 4, there was wide variability, with some participants having a marked increase in BMD, whilst others remained stable or decreased. Studies have shown that BMD decreases with age and GC use in DMD and falls further still when boys lose ambulation $(25,26,27,28)$. The presence of vertebral fracture can also spuriously elevate BMD which makes the

Table 5 Outcome variables before and after a 2-year incremental regimen of intramuscular testosterone. Data are presented as mean (S.D.).

\begin{tabular}{|c|c|c|}
\hline & $\begin{array}{c}\text { Before } \\
\text { testosterone }\end{array}$ & $\begin{array}{c}\text { After } \\
\text { testosterone }\end{array}$ \\
\hline Height (cm) & $133.6(10.7)$ & $142.4(7.4)$ \\
\hline Height z-score & $-3.17(1.34)$ & $-3.44(1.06)$ \\
\hline Target height $(\mathrm{cm})$ & $183.3(4.6)$ & \\
\hline Weight (kg) & $48.3(12.4)$ & $52.8(12.2)$ \\
\hline Weight z-score & $-0.19(1.56)$ & $-0.94(1.81)$ \\
\hline $\mathrm{BMI}\left(\mathrm{kg} / \mathrm{m}^{2}\right)$ & $26.8(4.5)$ & $26.3(5.0)$ \\
\hline BMI z-score & $2.16(0.9)$ & $1.64(1.35)$ \\
\hline Lean mass index $\left(\mathrm{kg} / \mathrm{m}^{2}\right)$ & $12.4(2.3)$ & $12.8(2.9)$ \\
\hline Fat mass index $\left(\mathrm{kg} / \mathrm{m}^{2}\right)$ & $13.6(4.2)$ & $12.5(4.3)$ \\
\hline $\begin{array}{l}\text { NSAA (if ambulant at } \\
\text { both timepoints) }\end{array}$ & $18(8.88)$ & $13(7.23)$ \\
\hline PUL & $33.9(6.72)$ & $30.9(8.66)$ \\
\hline LS BMAC z-score & $0.22(2.21)$ & $0.35(2.21)$ \\
\hline
\end{tabular}

data harder to interpret. The process of puberty is vital for an increase in bone size and bone mineral content. Androgen deficiency is a risk factor for osteoporosis and fracture and early initiation of androgen therapy is associated with improved bone mineral density (29). Although fracture risk does not correlate directly with $\mathrm{BMD}$, these data suggest a possible bone protective effect of testosterone therapy, despite ongoing GC use. Many boys lose ambulation after they fall and fracture and if muscle mass and bone density can be optimised during puberty, ambulation may be maintained for longer. The change in mean PUL score over 2 years is consistent with published data (-3 points) (30), whereas the fall in mean NSAA score was slightly less than reported in the literature - mean drop of 4 points a year (31).

When arm muscle groups were combined, there were significant increases in both CSA and cCSA from baseline to 2 years. Only one participant (participant 7, nonambulant at baseline) had a significant increase in overall FF of the arm. The arm FF remained unchanged over the 2-year period, in contrast to the natural history of DMD. Our data contrast with a recent study of 15 non-ambulant boys with DMD (mean age 13.3 years) which found a progressive increase in FF (18). Only 7 boys completed that study and pubertal status was not recorded.

When leg muscle groups were combined and compared between baseline and 2 years, there were also increases in both CSA and CCSA. FF in most participants and muscle groups were stable over the 2-year study period and only increased in one participant. This challenges the results found in other studies $(32,33)$. 


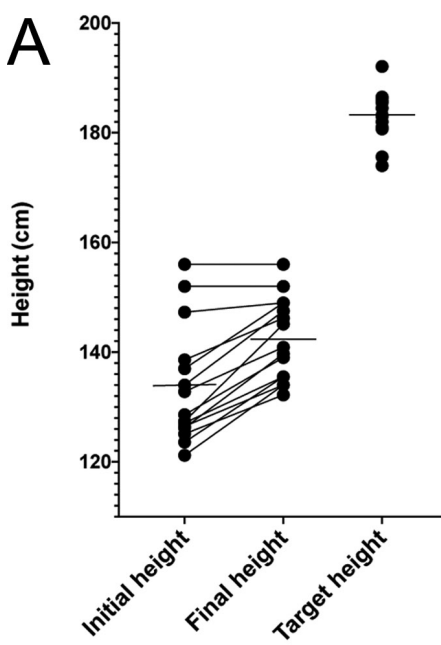

$\mathrm{B}$
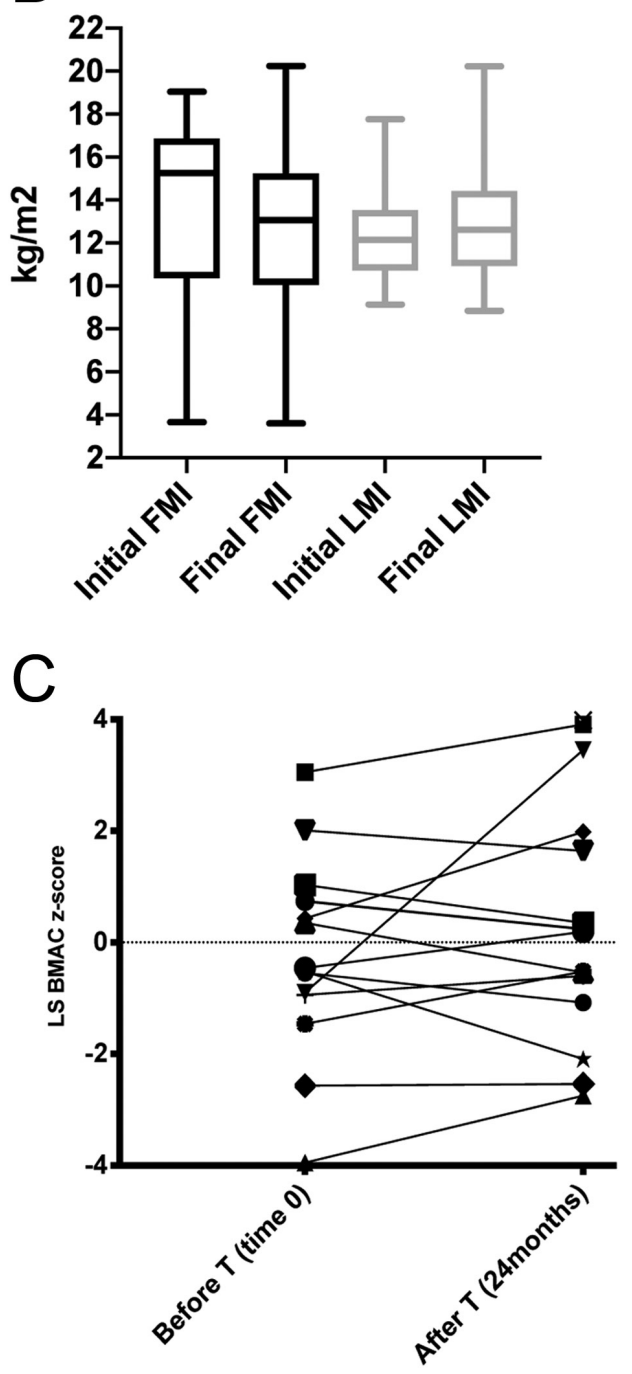

Figure 4

(A) Initial and final height of study participants with target height for comparison. Horizontal lines show mean values.
The CSA of all four muscle groups in the arm increased significantly over 2 years, showing the muscle growth that we would expect. The cCSA (that area which is not fat replaced) on the other hand only increased significantly for the FEG, suggesting that in this muscle group the growth of muscle volume outpaced the disease process, whereby fat replaces muscle and the FF results support this. When all muscle groups were considered together, there was no significant increase in fat fraction and significant increases in CSA and cCSA for arm and legs: muscle growth at least kept pace with chronic destruction. By contrast, the cCSA did not significantly increase in any of the arm muscle groups studied by Ricotti et al. (18).

The mean FF of the tibial bone marrow for the DMD boys was significantly higher than controls (Table 3). Many factors may contribute to BMD reduction including progressive muscle weakness and GC use, which cause increased bone marrow adiposity $(34,35)$, probably through a diversion in the mesenchymal progenitor cell line with increased adipogenesis $(36,37)$. Bone marrow $\mathrm{FF}$ has been suggested as a potential biomarker in postmenopausal women with fragility fractures (38).

The T2 relaxation times of all four compound muscle groups were significantly higher at baseline than controls, in keeping with an ongoing inflammatory process. This observation is consistent with some studies (39) but contrasts with others (32). The relaxation times for all groups except UFG (which was the least affected at baseline) decreased significantly at 2 years but remained higher than those of the controls at baseline. This may indicate a reduction in the inflammatory process after testosterone supplementation, as similar results have been demonstrated after 3 months of GC therapy in DMD (40). Androgens are known to have an anti-inflammatory effect, partly via their role in cytokine-suppression (41, 42 ) and may have a disease-ameliorating role in addition to the more well-characterised benefits of testosterone during puberty. It is possible, however, that $\mathrm{T} 2$ relaxation time may decrease once a boy loses ambulation and five boys lost ambulation over 2 years (32).

(B) Initial and final lean and fat mass index of study population. Box represents mean and standard deviation, whiskers show range. FMI, fat mass index; LMI, lean mass index. (C) Lumbar spine (size adjusted) bone mineral content (LSBMAC) z-score before and after a 2-year incremental regimen of intramuscular testosterone.. 
Table 6 Longitudinal results for fat fraction (FF), cross-sectional area (CSA) and contractile cross-sectional area (cCSA) when each muscle group is considered separately for 14 participants.

\begin{tabular}{|c|c|c|c|c|c|c|c|c|}
\hline \multirow[b]{3}{*}{ Muscle group } & \multicolumn{4}{|c|}{ FF, \% } & \multirow{2}{*}{\multicolumn{2}{|c|}{$\begin{array}{c}\text { CSA, } \mathbf{m m}^{\mathbf{2}} \\
\mathrm{DMD}\end{array}$}} & \multirow{2}{*}{\multicolumn{2}{|c|}{$\begin{array}{c}\mathbf{c C S A}, \mathbf{m m}^{\mathbf{2}} \\
\mathrm{DMD}\end{array}$}} \\
\hline & \multicolumn{3}{|c|}{ DMD } & \multirow[b]{2}{*}{ Control } & & & & \\
\hline & $\mathrm{BL}$ & 1 year & 2 years & & $\mathrm{BL}$ & 2 years & $\mathrm{BL}$ & 2 years \\
\hline BM & 99.3 & 99.3 & 99.2 & $88.9 *$ & - & - & - & - \\
\hline TA & 11.7 & 11.2 & 11.9 & $2.0^{\dagger}$ & 296 & $383^{\dagger}$ & 265 & $343^{\dagger}$ \\
\hline MG & 23.6 & 22.7 & 22.6 & $2.8^{\S}$ & 1216 & 1374 & 942 & 1090 \\
\hline LG & 28.7 & 28.0 & 28.5 & $2.5^{\S}$ & 549 & 644 & 371 & 443 \\
\hline SOL & 19.1 & 20.1 & 21.5 & $2.4^{\ddagger}$ & 1566 & 1611 & 1261 & 1274 \\
\hline RF & 51.9 & 53.9 & 51.5 & $1.6^{\S}$ & 500 & 548 & 237 & 258 \\
\hline VL & 50.8 & 51.5 & 51.8 & $2.0^{\S}$ & 994 & 1069 & 489 & 515 \\
\hline BFLH & 59.5 & 61.4 & 62.0 & $2.7^{\S}$ & 839 & 856 & 316 & 335 \\
\hline ST & 28.2 & 27.8 & 32.7 & $2.7^{\ddagger}$ & 508 & $612^{\dagger}$ & 375 & 425 \\
\hline SART & 24.9 & 26.1 & 27.5 & $5.1^{\S}$ & 215 & $244 *$ & 163 & 178 \\
\hline TOTAL & 33.9 & 34.1 & 33.8 & $2.4^{\ddagger}$ & 6683 & $7341^{\ddagger}$ & 4419 & $4861^{\dagger}$ \\
\hline
\end{tabular}

${ }^{*} P<0.05 ;{ }^{\dagger} P<0.01 ;{ }^{\ddagger} P<0.001 ;{ }^{\S} P<0.0001-P$ values in the control column are unpaired $t$-tests vs DMD baseline, $P$ values in DMD 1 and 2 years are paired $t$-tests vs DMD baseline.

$\mathrm{BFLH}$, biceps femoris long head; BL, baseline; BM, bone marrow; LG, lateral gastrocnemius; MG, medial gastrocnemius; RF, rectus femoris; SART, sartorius; SOL, soleus; ST, semitendinosus; TA, tibialis anterior; VL, vastus lateralis.

\section{Limitations of the study}

Although we wanted to perform a randomised doubleblinded clinical trial, the Research Ethics Committee felt that it would be inappropriate to withhold treatment for a period of 2 years in this cohort, particularly as our audit suggested that it was well-liked (8). Furthermore, physical development during puberty precludes the use of a placebo. By standardising the regimen, investigations and collection of the adverse event profile and safety data that are required as part of a rigorous clinical trial methodology, this has enabled us to systematically evaluate the tolerability and efficacy of this regimen. The study was small, and the recruitment target was pragmatic within a 1 year window at our centre. It was therefore underpowered to detect differences in some of the secondary outcomes such as BMAD and body composition.

\section{Conclusion}

A 2-year incremental regimen of 4-weekly intramuscular testosterone injections in prepubertal boys with DMD was safe, well-tolerated, associated with high satisfaction scores and resulted in endogenous gonadotropin release when exogenous testosterone was stopped. Height increased in most individuals and there was evidence to suggest a favourable impact on bone density, muscle morphology and muscle function. Our data support the routine use of exogenous androgen in boys with DMD who are on GC, as recommended in the revised DMD standards of care.

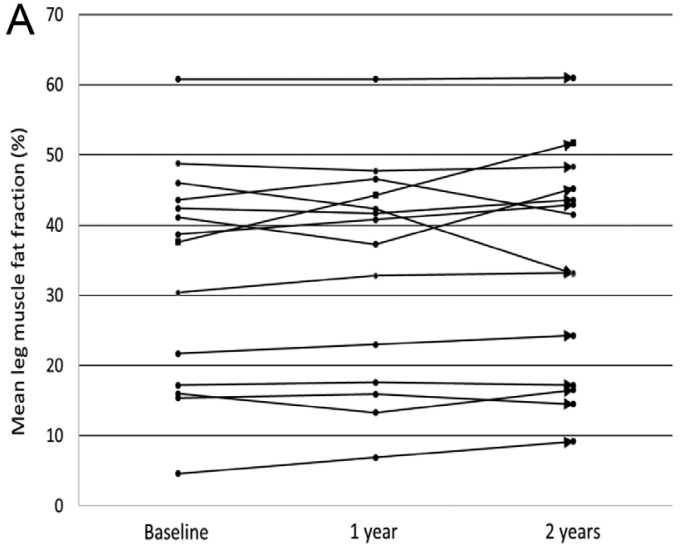

$\mathrm{B}$

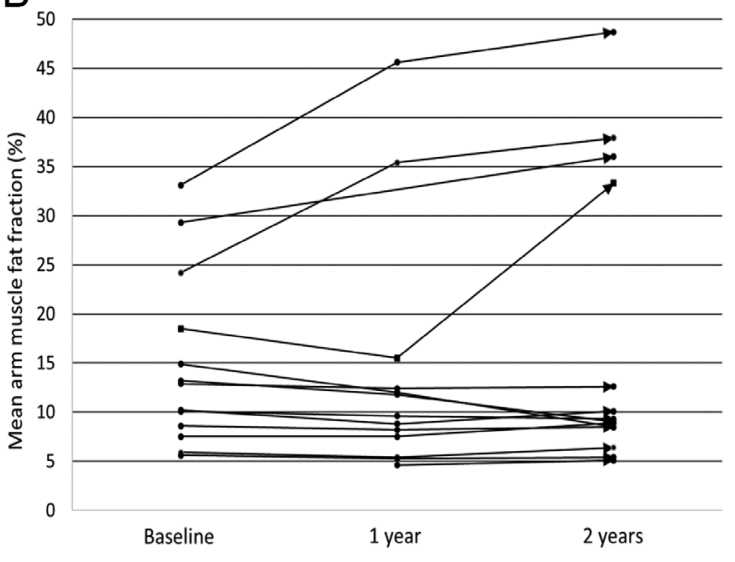

Figure 5

Progression of mean muscle fat fraction for the 14 individuals over the 2-year testosterone supplementation period. (A) Overall leg muscle fat fraction, (B) Overall arm muscle fat fraction (note one missing data point at baseline and 1 year).. 
Table 7 Longitudinal results for fat fraction (FF, \%), mean T2 relaxation time (ms), cross-sectional area (CSA, mm²) and contractile cross-sectional area (cCSA, $\mathrm{mm}^{2}$ ), when each muscle group is considered separately for the participants.

\begin{tabular}{|c|c|c|c|c|c|}
\hline \multirow{3}{*}{$\begin{array}{l}\text { Muscle } \\
\text { group }\end{array}$} & \multirow[b]{3}{*}{$N$} & \multicolumn{4}{|c|}{$\mathrm{T} 2, \mathrm{~ms}$} \\
\hline & & \multicolumn{3}{|c|}{ DMD } & \multirow[b]{2}{*}{ Control } \\
\hline & & $\mathrm{BL}$ & 1 year & 2 years & \\
\hline FEG & 12 & 31.0 & 31.0 & $29.5^{\ddagger}$ & $28.3^{\S}$ \\
\hline UEG & 12 & 32.4 & 32.1 & $31.2^{\dagger}$ & $29.5^{\ddagger}$ \\
\hline FFG & 12 & 31.5 & 31.2 & $29.6^{\dagger}$ & $28.5^{\S}$ \\
\hline UFG & 13 & 30.4 & 30.2 & 30.2 & $29.1 *$ \\
\hline Total & & & & & \\
\hline
\end{tabular}

\begin{tabular}{|c|c|c|c|}
\hline \multicolumn{4}{|c|}{ FF, \% } \\
\hline \multicolumn{3}{|c|}{ DMD } & \multirow[b]{2}{*}{ Control } \\
\hline $\mathrm{BL}$ & 1 year & 2 years & \\
\hline 11.5 & 10.3 & 11.5 & $3.9^{\ddagger}$ \\
\hline 13.6 & 16.1 & 18.8 & $3.4^{\dagger}$ \\
\hline 13.2 & 12.8 & 13.3 & $3.7^{\dagger}$ \\
\hline 17.0 & 21.2 & $24.8^{*}$ & $3.6^{+}$ \\
\hline 12.3 & 11.8 & 14.6 & $3.6 *$ \\
\hline
\end{tabular}

\begin{tabular}{|c|c|}
\hline \multicolumn{2}{|c|}{ CSA, $\mathrm{mm}^{2}$} \\
\hline \multicolumn{2}{|c|}{ DMD } \\
\hline $\mathrm{BL}$ & 2 years \\
\hline 397 & $501 *$ \\
\hline 865 & $960 *$ \\
\hline 849 & $911 *$ \\
\hline 564 & $630 *$ \\
\hline 2675 & $3002^{\dagger}$ \\
\hline
\end{tabular}

\begin{tabular}{|c|c|}
\hline \multicolumn{2}{|c|}{ cCSA, $\mathbf{m m}^{2}$} \\
\hline \multicolumn{2}{|c|}{ DMD } \\
\hline $\mathrm{BL}$ & 2 years \\
\hline 354 & $450^{*}$ \\
\hline 749 & 808 \\
\hline 762 & 815 \\
\hline 480 & 490 \\
\hline 2345 & $2563^{*}$ \\
\hline
\end{tabular}

${ }^{\star} P<0.05 ;{ }^{\dagger} P<0.01 ;{ }^{\ddagger} P<0.001 ;{ }^{\S} P<0.0001-P$ values in the control column are unpaired $t$-tests vs DMD baseline, $P$ values in DMD 1 and 2 years are paired $t$-tests vs DMD baseline.

FEG, forearm extensor group; FFG, forearm flexor group; UEG, upper arm extensor group; UFG, upper arm flexor group.

It is unclear whether endogenous testosterone production will remain adequate in the longer term.

\section{Supplementary materials}

This is linked to the online version of the paper at https://doi.org/10.1530/ EJE-20-0709.

\section{Declaration of interest}

Volker Straub has received speaker honoraria from Sanofi Genzyme and is or has recently been on advisory boards for Audentes Therapeutics, AveXis, Biogen, Exonics Therapeutics/Vertex, Roche, Sarepta Therapeutics and Wave Therapeutics. He has research collaborations with Ultragenyx and Sanofi Genzyme. Robert Muni Lofra has received speaker honoraria from Biogen and has been recently on advisory boards for Roche and Biogen. Anna Mayhew has participated in SAB meetings for Summit, PTC and Biogen and performs Consultancy work (training physiotherapists) for: Roche, Pfizer, PTC, Summit, Sarepta, Santhera, Italfarmaco, Amicus, Biogen and Avexis. Michela Guglieri has received speaker honoraria from Sarepta and is or has been on advisory boards for PTC Therapeutics and Pfizer. Claire Wood, Kieren Hollingsworth, Eric Hughes, Sadha Punniyakodi, Rod Mitchell and Tim Cheetham have no conflicts of interest.

\section{Funding}

The study was generously funded by Duchenne Now. C W was funded by the Medical Research Council/MDUK (MR/N020588/1). E H was funded by the European Commission Horizon 2020 (Grant no. 667078).

\section{Author contribution statement}

Timothy D Cheetham and Volker Straub denotes equal contribution as senior author.

\section{Acknowledgements}

With thanks to the participants and their families for giving up their time to take part in this study. Yolanda Ailins-Sahun, Jonathan Foggin, Meredith James, Dionne Moat, Jas Sodhi, the nursing staff in the CRF and the Clinical trials unit at Newcastle University for their help in collecting and analysing data. Simon Pearce, Terry Aspray, Cathy Turner and Pauline McCormack for their roles in the Testosterone Steering Committee. Tim Hodgson, Dot Wallace and Louise Ward, Senior Research Radiographers at the Newcastle Magnetic Resonance Centre for acquiring the MRI data.

\section{References}

1 Emery AE. Population frequencies of inherited neuromuscular diseases - a world survey. Neuromuscular Disorders 1991 19-29. (https://doi.org/10.1016/0960-8966(91)90039-u)

2 Deconinck AE, Rafael JA, Skinner JA, Brown SC, Potter AC, Metzinger L, Watt DJ, Dickson JG, Tinsley JM \& Davies KE. Utrophindystrophin-deficient mice as a model for Duchenne muscular dystrophy. Cell 199790 717-727. (https://doi.org/10.1016/s00928674(00)80532-2)

3 Moxley RT, Pandya S, Ciafaloni E, Fox DJ \& Campbell K. Change in natural history of Duchenne muscular dystrophy with longterm corticosteroid treatment: implications for management. Journal of Child Neurology 201025 1116-1129. (https://doi. org/10.1177/0883073810371004)

4 Daftary AS, Crisanti M, Kalra M, Wong B \& Amin R. Effect of longterm steroids on cough efficiency and respiratory muscle strength in patients with Duchenne muscular dystrophy. Pediatrics 2007119 e320-e324. (https://doi.org/10.1542/peds.2006-1400)

5 Lebel DE, Corston JA, McAdam LC, Biggar WD \& Alman BA. Glucocorticoid treatment for the prevention of scoliosis in children with Duchenne muscular dystrophy: long-term follow-up. Journal of Bone and Joint Surgery: American Volume 201395 1057-1061. (https:// doi.org/10.2106/JBJS.L.01577)

6 Wood CL, Straub V, Guglieri M, Bushby K \& Cheetham T. Short stature and pubertal delay in Duchenne muscular dystrophy. Archives of Disease in Childhood 2016101 101-106. (https://doi.org/10.1136/ archdischild-2015-308654)

7 Wang C, Alexander G, Berman N, Salehian B, Davidson T, McDonald V, Steiner B, Hull L, Callegari C \& Swerdloff RS Testosterone replacement therapy improves mood in hypogonadal men - a clinical research center study. Journal of Clinical Endocrinology and Metabolism 199681 3578-3583. (https://doi.org/10.1210/ jcem.81.10.8855804)

8 Wood CL, Cheetham TD, Guglieri M, Bushby K, Owen C, Johnstone H \& Straub V. Testosterone treatment of pubertal delay in Duchenne muscular dystrophy. Neuropediatrics 201546 371-376. (https://doi.org/10.1055/s-0035-1563696)

9 Wood CL, Cheetham TD, Hollingsworth KG, Guglieri M, AilinsSahun Y, Punniyakodi S, Mayhew A \& Straub V. Observational study of clinical outcomes for testosterone treatment of pubertal delay in Duchenne muscular dystrophy. BMC Pediatrics 201919 131. (https:// doi.org/10.1186/s12887-019-1503-x)

10 Atkinson MJ, Sinha A, Hass SL, Colman SS, Kumar RN, Brod M \& Rowland CR. Validation of a general measure of treatment satisfaction, the Treatment Satisfaction Questionnaire for Medication (TSQM), using a national panel study of chronic disease. Health and Quality of Life Outcomes 20042 12. (https://doi.org/10.1186/1477-7525-2-12) 
11 Marshall WA \& Tanner JM. Variations in the pattern of pubertal changes in boys. Archives of Disease in Childhood 197045 13-23. (https://doi.org/10.1136/adc.45.239.13)

12 Greulich WW \& Pyle SI Radiographic Atlas of Skeletal Development of the Hand and Wrist, 2nd ed. California: Stanford University Press, 1959.

13 Mayhew A, Mazzone ES, Eagle M, Duong T, Ash M, Decostre V, Vandenhauwe M, Klingels K, Florence J, Main M et al. Development of the performance of the upper limb module for Duchenne muscular dystrophy. Developmental Medicine and Child Neurology 2013 55 1038-1045. (https://doi.org/10.1111/dmcn.12213)

14 Mayhew AG, Cano SJ, Scott E, Eagle M, Bushby K, Manzur A, Muntoni F \& North Star Clinical Network for Neuromuscular Disease. Detecting meaningful change using the North Star Ambulatory Assessment in Duchenne muscular dystrophy. Developmental Medicine and Child Neurology 201355 1046-1052. (https://doi.org/10.1111/ dmcn.12220)

15 Hollingsworth KG, Higgins DM, McCallum M, Ward L, Coombs A $\&$ Straub V. Investigating the quantitative fidelity of prospectively undersampled chemical shift imaging in muscular dystrophy with compressed sensing and parallel imaging reconstruction. Magnetic Resonance in Medicine 201472 1610-1619. (https://doi.org/10.1002/ mrm.25072)

16 Loughran T, Higgins DM, McCallum M, Coombs A, Straub V \& Hollingsworth KG. Improving highly accelerated fat fraction measurements for clinical trials in muscular dystrophy: origin and quantitative effect of R2* changes. Radiology 2015275 570-578. (https://doi.org/10.1148/radiol.14141191)

17 Carlier PG. Global T2 versus water T2 in NMR imaging of fatty infiltrated muscles: different methodology, different information and different implications. Neuromuscular Disorders 201424 390-392. (https://doi.org/10.1016/j.nmd.2014.02.009).

18 Ricotti V, Evans MRB, Sinclair CDJ, Butler JW, Ridout DA, Hogrel JY, Emira A, Morrow JM, Reilly MM, Hanna MG et al. Upper limb evaluation in Duchenne muscular dystrophy: fat-water quantification by MRI, muscle force and function define endpoints for clinical trials. PLOS ONE 201611 e0162542. (https://doi. org/10.1371/journal.pone.0162542)

19 Birnkrant DJ, Bushby K, Bann CM, Apkon SD, Blackwell A, Brumbaugh D, Case LE, Clemens PR, Hadjiyannakis S, Pandya S et al. Diagnosis and management of Duchenne muscular dystrophy, Part 1: diagnosis, and neuromuscular, rehabilitation, endocrine, and gastrointestinal and nutritional management. Lancet: Neurology 201817 251-267. (https://doi.org/10.1016/S14744422(18)30024-3)

20 Sakakura M, Takebe K \& Nakagawa S. Inhibition of luteinizing hormone secretion induced by synthetic LRH by long-term treatment with glucocorticoids in human subjects. Journal of Clinical Endocrinology and Metabolism 197540 774-779. (https://doi. org/10.1210/jcem-40-5-774)

21 MacAdams MR, White RH \& Chipps BE. Reduction of serum testosterone levels during chronic glucocorticoid therapy. Annals of Internal Medicine 1986104 648-651. (https://doi.org/10.7326/00034819-104-5-648)

22 Biggar WD, Harris VA, Eliasoph L \& Alman B. Long-term benefits of deflazacort treatment for boys with Duchenne muscular dystrophy in their second decade. Neuromuscular Disorders 200616 249-255. (https://doi.org/10.1016/j.nmd.2006.01.010)

23 Annexstad EJ, Bollerslev J, Westvik J, Myhre AG, Godang K, Holm I $\&$ Rasmussen M. The role of delayed bone age in the evaluation of stature and bone health in glucocorticoid treated patients with Duchenne muscular dystrophy. International Journal of Pediatric Endocrinology 20192019 4. (https://doi.org/10.1186/s13633-019. 0070-0)

24 Al-Zougbi A, Mathews KD \& Shibli-Rahhal A. Use of bone age for evaluating bone density in patients with Duchenne muscular dystrophy: a preliminary report. Muscle and Nerve 201959 422-425 (https://doi.org/10.1002/mus.26413)

25 Larson CM \& Henderson RC. Bone mineral density and fractures in boys with Duchenne muscular dystrophy. Journal of Pediatric Orthopedics 200020 71-74. (https://doi.org/10.1097/01241398200001000-00016)

26 McDonald DG, Kinali M, Gallagher AC, Mercuri E, Muntoni F, Roper H, Jardine P, Jones DH \& Pike MG. Fracture prevalence in Duchenne muscular dystrophy. Developmental Medicine and Child Neurology 200244 695-698. (https://doi.org/10.1017/ s0012162201002778)

27 King WM, Ruttencutter R, Nagaraja HN, Matkovic V, Landoll J, Hoyle C, Mendell JR \& Kissel JT. Orthopedic outcomes of long-term daily corticosteroid treatment in Duchenne muscular dystrophy. Neurology 200768 1607-1613. (https://doi.org/10.1212/01. wnl.0000260974.41514.83)

28 James KA, Cunniff C, Apkon SD, Mathews K, Lu Z, Holtzer C, Pandya S, Ciafaloni E \& Miller L. Risk factors for first fractures among males with duchenne or Becker muscular dystrophy. Journal of Pediatric Orthopedics 201535 640-644. (https://doi.org/10.1097/ BPO.0000000000000348)

29 Katznelson L, Finkelstein JS, Schoenfeld DA, Rosenthal DI, Anderson EJ \& Klibanski A. Increase in bone density and lean body mass during testosterone administration in men with acquired hypogonadism. Journal of Clinical Endocrinology and Metabolism 1996 81 4358-4365. (https://doi.org/10.1210/jcem.81.12.8954042)

30 Mayhew AG, Coratti G, Mazzone ES, Klingels K, James M, Pane M, Straub V, Goemans N, Mercuri E, Ricotti V et al. Performance of upper limb module for Duchenne muscular dystrophy. Developmental Medicine and Child Neurology 202063 633-639. (https://doi. $\operatorname{org} / 10.1111 /$ dmcn.14361)

31 Mercuri E, Coratti G, Messina S, Ricotti V, Baranello G, D'Amico A, Pera MC, Albamonte E, Sivo S, Mazzone ES et al. Revised north star ambulatory assessment for young boys with Duchenne muscular dystrophy. PLOS ONE 201611 e0160195. (https://doi.org/10.1371/ journal.pone.0160195)

32 Wary C, Azzabou N, Giraudeau C, Louër J Le, Montus M, Voit T, Servais L \& Carlier P. Quantitative NMRI and NMRS identify augmented disease progression after loss of ambulation in forearms of boys with Duchenne muscular dystrophy. NMR in Biomedicine 201528 1150-1162. (https://doi.org/10.1002/nbm.3352)

33 Hogrel JY, Wary C, Moraux A, Azzabou N, Decostre V, Ollivier G, Canal A, Lilien C, Ledoux I, Annoussamy M et al. Longitudinal functional and NMR assessment of upper limbs in Duchenne muscular dystrophy. Neurology 201686 1022-1030. (https://doi. org/10.1212/WNL.0000000000002464)

34 Li GW, Xu Z, Chen QW, Chang SX, Tian YN \& Fan JZ. The temporal characterization of marrow lipids and adipocytes in a rabbit model of glucocorticoid-induced osteoporosis. Skeletal Radiology $2013 \mathbf{4 2}$ 1235-1244. (https://doi.org/10.1007/s00256-013-1659-7)

35 Lovdel A, Suchacki K, Sulston RJ, Wallace RJ, Macpherson G, Stimson RH, Homer NZ, Chapman KE \& Cawthorn WP. Investigating glucocorticoids as mediators of increased bone marrow adiposity during caloric restriction. Endocrine Abstracts 201856 GP58. (https:// doi.org/10.1530/endoabs.56.GP58)

36 Ito S, Suzuki N, Kato S, Takahashi T \& Takagi M. Glucocorticoids induce the differentiation of a mesenchymal progenitor cell line, ROB-C26 into adipocytes and osteoblasts, but fail to induce terminal osteoblast differentiation. Bone 2007 40 84-92. (https://doi. org/10.1016/j.bone.2006.07.012)

37 Tencerova M \& Kassem M. The bone marrow-derived stromal cells: commitment and regulation of adipogenesis. Frontiers in Endocrinology 20167 127. (https://doi.org/10.3389/ fendo.2016.00127)

38 Paccou J, Hardouin P, Cotten A, Penel G \& Cortet B. The role of bone marrow fat in skeletal health: usefulness and perspectives for 
clinicians. Journal of Clinical Endocrinology and Metabolism 2015100 3613-3621. (https://doi.org/10.1210/jc.2015-2338)

39 Willcocks RJ, Triplett WT, Forbes SC, Arora H, Senesac CR, Lott DJ, Nicholson TR, Rooney WD, Walter GA \& Vandenborne K. Magnetic resonance imaging of the proximal upper extremity musculature in boys with Duchenne muscular dystrophy. Journal of Neurology 2017 264 64-71. (https://doi.org/10.1007/s00415-016-8311-0)

40 Arpan I, Willcocks RJ, Forbes SC, Finkel RS, Lott DJ, Rooney WD, Triplett WT, Senesac CR, Daniels MJ, Byrne BJ et al. Examination of effects of corticosteroids on skeletal muscles of boys with DMD using
MRI and MRS. Neurology 201483 974-980. (https://doi.org/10.1212/ WNL.0000000000000775)

41 Bianchi VE. The anti-inflammatory effects of testosterone. Journal of the Endocrine Society 20193 91-107. (https://doi.org/10.1210/js.201800186)

42 Malkin CJ, Pugh PJ, Jones RD, Kapoor D, Channer KS \& Jones TH. The effect of testosterone replacement on endogenous inflammatory cytokines and lipid profiles in hypogonadal men. Journal of Clinical Endocrinology and Metabolism 200489 3313-3318. (https://doi. org/10.1210/jc.2003-031069)

Received 25 June 2020

Revised version received 3 September 2020

Accepted 8 October 2020 